\title{
A Case of Malignant T-Cell Lymphoma of Gastric Origin Accompanied by Pyothorax
}

\author{
Naoki Asakage Tetsurou Yamamoto $^{a} \quad$ Takahisa Suzuki $^{a}$

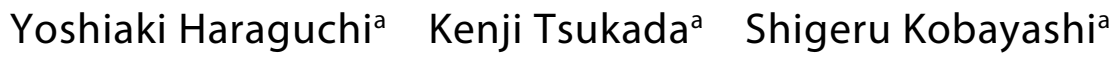 \\ Shigetaka Yamasaki ${ }^{\text {b }}$

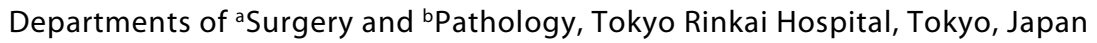

\section{Key Words}

Malignant T-cell lymphoma · Primary gastric · Pyothorax

\begin{abstract}
The patient was a 74-year-old man suffering from tuberculotic chronic pyothorax. He had hematemesis in January 2006. Hb was $6.1 \mathrm{~g} / \mathrm{dl}$. A type 2 tumor $3 \mathrm{~cm}$ in diameter was found in the vaulted region on the greater curvature side. It was diagnosed as a malignant lymphoma. WBC and differential count were normal, and the patient tested negative for HTVL-1 antibody. sIL2-R was elevated to $1,500 \mathrm{U} / \mathrm{ml}$. The superficial lymph nodes were not palpable. CT examination was not remarkable for the liver and spleen. There was no generalized lymph node enlargement. Based on these findings, a diagnosis of malignant lymphoma of gastric origin was made. As the patient had respiratory disorders, too, wedge-shaped gastrectomy was performed to inhibit invasion.

Pathological examination revealed CD3 positive large atypical lymphocytes diffusely, EBV positive, HP negative. As a result, a diagnosis of non-Hodgkin T-cell lymphoma was made. The tumor did not return for 1 year and 8 months after surgery, but the patient died of sudden aggravation of respiratory disorders in September 2007. Pathological anatomy was performed. The gastric remnant was left with lymphoma, and the bone marrow and systemic lymph nodes were negative for a malignant lymphoma. The possibility of stomach metastasis from the preoperative pyothorax-related malignant lymphoma was considered, but was ruled out because the lungs were devoid of a malignant lymphoma. We report a case of an extremely rare malignant T-cell lymphoma of gastric origin.
\end{abstract}

\section{Introduction}

Malignant gastrointestinal lymphoma usually originates from the stomach and is mostly derived from $\mathrm{B}$ cells and rarely from $\mathrm{T}$ cells [1]. We treated a patient with 
malignant T-cell lymphoma of gastric origin accompanied by chronic tuberculous pyothorax, which required differentiation from gastric metastases of adult T-cell leukemia/lymphoma, EBV-associated malignant lymphoma, which is also known as pyothorax-associated lymphoma (PAL) [2, 3], and primary effusion lymphoma (PEL) [4].

\section{Case Report}

The patient was a 74-year-old man with the chief complaints of hematemesis and anemia. He had a history of tuberculous pleurisy. He had smoked 50 cigarettes daily for 50 years or more. In May 2005, he was hospitalized with pneumonia and acute heart failure. Thoracic drainage was performed because of right pyothorax. He had been suffering from chronic arteriosclerosis for 6 years and had been on anticoagulant therapy since a stent was inserted into his left external iliac artery in July 2005. In January 2006, hematemesis occurred, but he did not seek treatment. When he attended the outpatient clinic in February 2006, his $\mathrm{Hb}$ was $8.0 \mathrm{~g} / \mathrm{dl}$. Subsequently anemia progressed $(\mathrm{Hb} 6.1 \mathrm{~g} / \mathrm{dl})$ and black stools were noted. He underwent gastroscopy and was hospitalized because a tumor was detected on the greater curvature of the gastric body.

On admission, there was obvious anemia and breath sounds were reduced on the right side. The abdomen was flat and hepatosplenomegaly was not detected. Hb was $6.1 \mathrm{~g} / \mathrm{dl}$, suggesting severe anemia, but the differential WBC count was not abnormal. CEA was slightly increased to $6.1 \mathrm{ng} / \mathrm{ml}$. The patient was positive for EBV antibody and negative for HTLV-1/HIV antibodies, while sIL2-R was elevated to $1,500 \mathrm{U} / \mathrm{ml}$ (table 1$)$.

Chest X-ray revealed a lesion protruding into the thoracic cavity from the right chest wall, which was probably a pyothorax, and a nodule in the left upper lung field (fig. 1a). Abdominal X-ray showed no abnormalities other than pyelectasis. Gastroscopy revealed a sharply defined prominent lesion approximately $3 \mathrm{~cm}$ in diameter located at the fornix of the stomach. It was a type 2 tumor with a central ulcer (fig. 2a). The patient was negative for Helicobacter pylori. Biopsy strongly suggested that the tumor was a malignant lymphoma. Chest and abdominal CT showed a collection of fluid surrounded by calcified and thickened pleura on the right lower chest wall, which was thought to be an old pyothorax (fig. 1b). In the abdomen, there was a contrast-enhanced tumor on the posterior wall of the gastric fornix (fig. $2 b$ ), but there were no abnormalities of the liver or spleen and perigastric lymphadenopathy was not detected. Ga scintigraphy noted increased uptake in the mediastinum. Iliac marrow aspiration biopsy showed CD3-positive lymphocyte-like cells in some areas. Otorhinological examination revealed nothing abnormal. Potential sources of hemorrhage were not detected in any other part of the gastrointestinal tract.

Based on these findings, malignant T-cell lymphoma of the stomach was diagnosed. It was stage IV according to the Cotswolds classification [5], but whether it was primary or secondary was unclear. Since anemia progressed and the patient had a history of respiratory impairment due to chronic pyothorax as well as pneumonia and acute heart failure, invasive surgery was performed in March 2006 to remove the source of hemorrhage. Laparotomy was performed by making a median incision in the upper abdomen. Ascites was not noted, and there were no abnormalities of the liver or spleen. Since there was no perigastric lymphadenopathy, wedge resection of the stomach was performed to remove the tumor.

Macroscopic observation revealed a prominent tumor $3 \mathrm{~cm}$ in diameter with an ulcer at its center located slightly towards the posterior wall on the greater curvature of the gastric fornix, which was of the collapsed type according to Sano's classification. Within the tumor, large atypical lymphocytes showed diffuse proliferation, and the depth of invasion was classified as subserosal (fig. 3 a). Immunohistologically, the tumor was positive for $\mathrm{CD} 3$ (fig. 3b), while it was negative for CD20, CD56, and CD57. Therefore the patient was diagnosed as having non-Hodgkin T-cell lymphoma, the diagnosis being unspecified peripheral T-cell lymphoma [6] according to the WHO Classification [7].

Postoperatively there was no recurrence of anemia. Chest/abdominal CT scans revealed no changes of the right pyothorax or lymphadenopathy. The sIL2-R level decreased gradually, but still remained high. Ga scintigraphy showed the disappearance of abnormal uptake in the mediastinum. Chemotherapy was not performed because the patient strongly refused it. There were no signs of recurrence for 20 months after surgery, but the patient died in September 2007 because of rapid deterioration of respiratory function. At autopsy, malignant lymphoma was not detected in the residual stomach, lungs, bone marrow, or lymph nodes. In the upper lobe of the left lung, there was an epithelioid cell granuloma accompanied by caseous necrosis which was positive for Ziehl-Neelsen stain. 
A chronic right pyothorax was also noted, but there were no findings suggesting malignant lymphoma or tuberculosis.

\section{Discussion}

Approximately $10 \%$ of all malignant lymphomas originate from the gastrointestinal tract, with $60-80 \%$ of gastrointestinal malignant lymphomas arising from the stomach and most of these tumors being derived from B cells [8]. On the other hand, malignant $\mathrm{T}$-cell lymphoma of gastric origin is rare, accounting for approximately $6 \%$ of gastric malignant lymphomas [1].

Malignant lymphoma of the stomach is classified as primary or secondary, but it is not always easy to differentiate these two tumor types [8]. The diagnostic criteria of Dawson et al. [9] are used for malignant lymphoma of intestinal origin, although the results of endoscopy, CT, and Ga scintigraphy have been used for this purpose in recent years [8]. In our patient, preoperative bone marrow aspiration revealed CD3-positive lymphocytes and Ga scintigraphy showed increased uptake in the mediastinum, so secondary malignant lymphoma was initially suspected and adult T-cell leukemia/lymphoma was considered to be the underlying disease. However, it was considered necessary to differentiate the tumor from gastric metastases of PAL and PEL (EBV-related malignant lymphomas or body-cavity based lymphoma) [10] because of the coexistence of chronic tuberculous pyothorax and the positive tests for EBV antibody. The possibility of these diseases was ruled out almost completely and the possibility of secondary malignant lymphoma was concluded to be low because the patient was negative for HTLV-1 antibody, because EBV-related malignant lymphoma or PAL and PEL usually arise from $\mathrm{B}$ cells and rarely from $\mathrm{T}$ cells, because pyothorax cytology revealed no lymphoma cells, and because CT detected no tumor around the pyothorax either before or after surgery. A diagnosis of malignant lymphoma of gastric origin was considered to be very likely because postoperative Ga scintigraphy only revealed abnormal uptake in the mediastinum, gastroscopy and CT showed no abnormalities, the diagnostic criteria of Dawson et al. were fulfilled, and there was no recurrence for 20 months postoperatively. Our patient was diagnosed as having Cotswolds stage IV malignant T-cell lymphoma because preoperative Ga scintigraphy showed increased uptake in the mediastinum and because iliac marrow aspiration suggested partial infiltration of CD3-positive lymphocyte-like cells. However, autopsy found no malignant lymphoma in the thoracic cavity, mediastinum or bone marrow, so the CD3-positive lymphocytes observed in the marrow before surgery were regarded as non-tumorous. The persistently high sIL2-R level noted during observation was not considered to be ascribable to recurrent malignant lymphoma, but rather to chronic inflammation associated with tuberculosis and chronic pyothorax.

Malignant lymphoma of gastric origin is treated by a combination of surgery, chemotherapy and radiotherapy. Total gastrectomy has been recommended as the procedure of first choice because multiple lesions are common and because there is a high rate of recurrence from the residual stomach [8]. In our patient, only gastric wedge resection of the tumor was done because Cotswolds stage IV malignant lymphoma was diagnosed preoperatively and the patient's general condition was poor. Postoperative chemotherapy was not performed because the patient refused it.

Among non-Hodgkin lymphoma, the prognosis of malignant B-cell lymphoma of gastric origin is relatively favorable. If the tumor is localized, it may be possible to cure it by local therapy alone $[1,8]$. However, unspecified peripheral T-cell lymphoma does not 
respond well to treatment, and the 1-year survival rate is low at around $20-30 \%$ [7]. Malignant T-cell lymphoma of gastric origin tends to undergo transformation to leukemia and its prognosis is poor (35.1\% of patients die within 1 year) [1]. However, it has also been reported that HTLV-1-negative patients with gastric T-cell lymphoma can have long survival [11]. In fact, there were no signs of recurrence during the follow-up period of 20 months without treatment, but our patient eventually died of respiratory insufficiency due to his other underlying diseases. If this had not happened, long survival could have been expected because it was demonstrated at autopsy that radical cure had been obtained by surgery.

Table 1. Hematology findings on admission

\begin{tabular}{|c|c|}
\hline $\mathrm{TP}, \mathrm{g} / \mathrm{dl}$ & 7.3 \\
\hline $\mathrm{Alb}, \mathrm{g} / \mathrm{dl}$ & 3.5 \\
\hline GOT, IU/l & 23 \\
\hline GPT, IU/l & 12 \\
\hline LDH, IU/l & 163 \\
\hline ALP, IU/l & 183 \\
\hline BUN, mg/dl & 10 \\
\hline $\mathrm{Cr}, \mathrm{mg} / \mathrm{dl}$ & 0.78 \\
\hline $\mathrm{Na}, \mathrm{mEq} / \mathrm{l}$ & 141 \\
\hline $\mathrm{K}, \mathrm{mEq} / \mathrm{l}$ & 105 \\
\hline $\mathrm{Cl}, \mathrm{mEq} / \mathrm{l}$ & 3.4 \\
\hline $\mathrm{WBC}, / \mu \mathrm{l}$ & 7,760 \\
\hline Stab, \% & 0 \\
\hline Seg, \% & 74.0 \\
\hline Eos, \% & 1.0 \\
\hline Baso, $\%$ & 1.0 \\
\hline Lymph, \% & 19.0 \\
\hline Mono, \% & 5.0 \\
\hline $\mathrm{RBC}, \times 10^{4} / \mu \mathrm{l}$ & 281 \\
\hline $\mathrm{Hb}, \mathrm{g} / \mathrm{dl}$ & 6.1 \\
\hline $\mathrm{Ht}, \%$ & 21.5 \\
\hline Plt, $\times 10^{4} / \mu \mathrm{l}$ & 47.1 \\
\hline $\mathrm{AFP}, \mathrm{ng} / \mathrm{ml}$ & 2.3 \\
\hline $\mathrm{CEA}, \mathrm{ng} / \mathrm{ml}$ & 6.1 \\
\hline CA $19-9, \mathrm{U} / \mathrm{ml}$ & 24.3 \\
\hline IL2-R, U/ml & 1,500 \\
\hline $\mathrm{EBV} \mathrm{Ab}$ & $(+)$ \\
\hline HTLV-1 Ab & $(-)$ \\
\hline H. pylori $\mathrm{Ab}$ & $(-)$ \\
\hline HIV Ab & $(-)$ \\
\hline
\end{tabular}




\begin{tabular}{r|l|l|l} 
Case Reports $/ \mathrm{h}$ & $\begin{array}{l}\text { Case Rep Gastroenterol 2009;3:162-168 } \\
\text { Dol: 10.1159/000223239 }\end{array}$ & Published online: June 16, 2009 & $\begin{array}{l}\text { O 2009 S. Karger AG, Basel } \\
\text { ISSN 1662-0631 } \\
\text { www.karger.com/crg }\end{array}$ \\
\hline
\end{tabular}

Fig. 1. a A shadow protruding from the right chest wall into the thoracic cavity and a nodular shadow in the left upper lung field were observed (arrows). b An obsolete empyema was observed along the right lower chest wall (arrows).

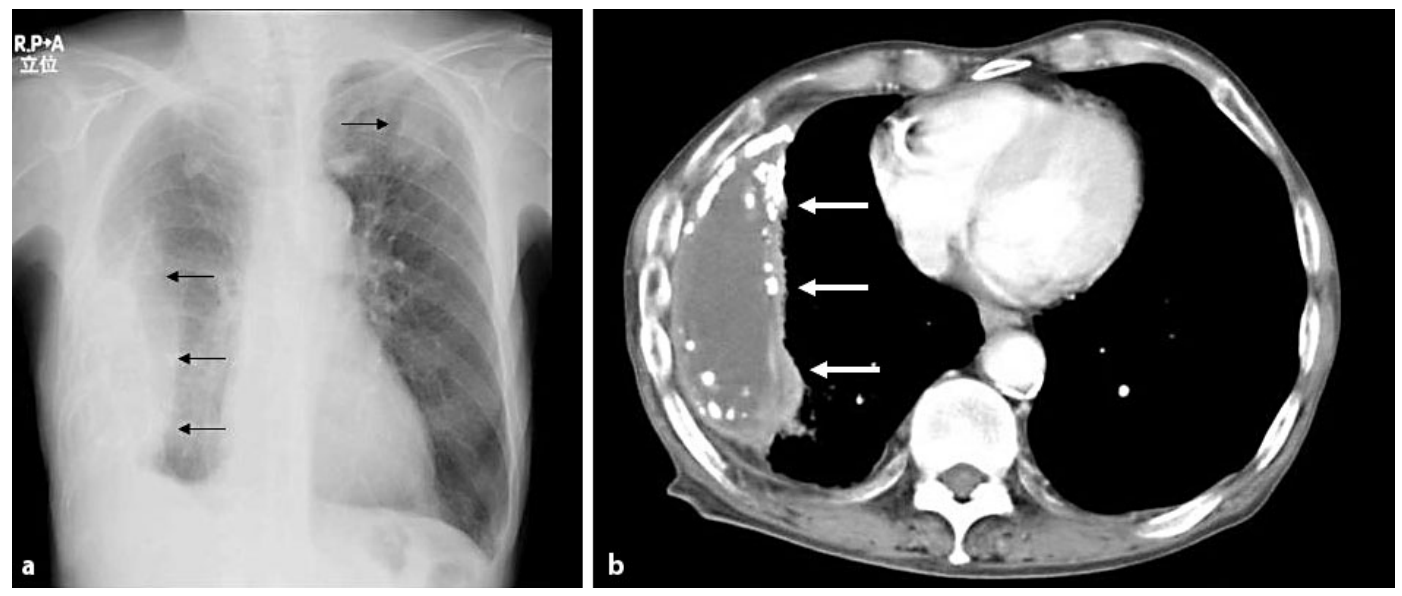

Fig. 2. a A type 2 tumor about $3 \mathrm{~cm}$ in diameter was seen in the vaulted region of the stomach. $\mathbf{b}$ An enhanced tumor was seen in the posterior wall of the vaulted region (arrows).

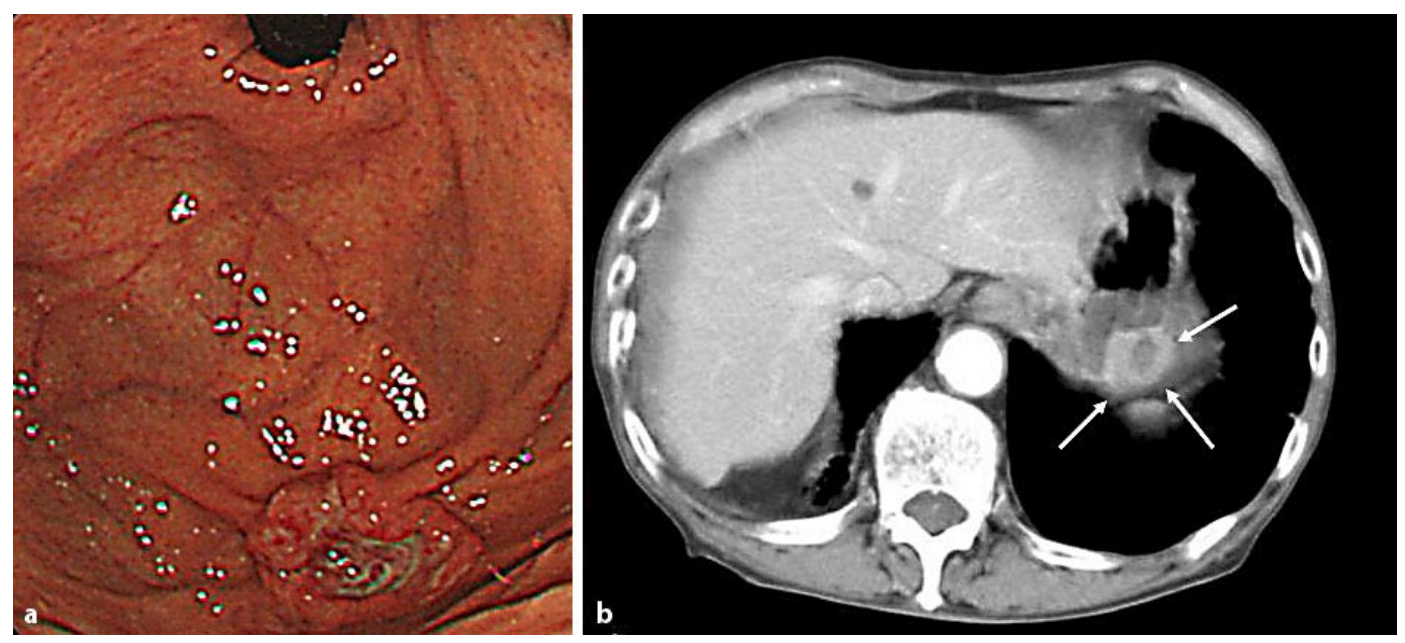




\begin{tabular}{r|l|l|l} 
Case Reports $/$ h & $\begin{array}{l}\text { Case Rep Gastroenterol 2009;3:162-168 } \\
\text { D01: 10.1159/000223239 }\end{array}$ & Published online: June 16, 2009 & $\begin{array}{l}\text { O 2009 S. Karger AG, Basel } \\
\text { ISSN 1662-0631 } \\
\text { www.karger.com/crg }\end{array}$ \\
\hline
\end{tabular}

Fig. 3. a Large atypical lymphocytes were increased diffusely in the tumor. b Immunopathologically CD3 positive.

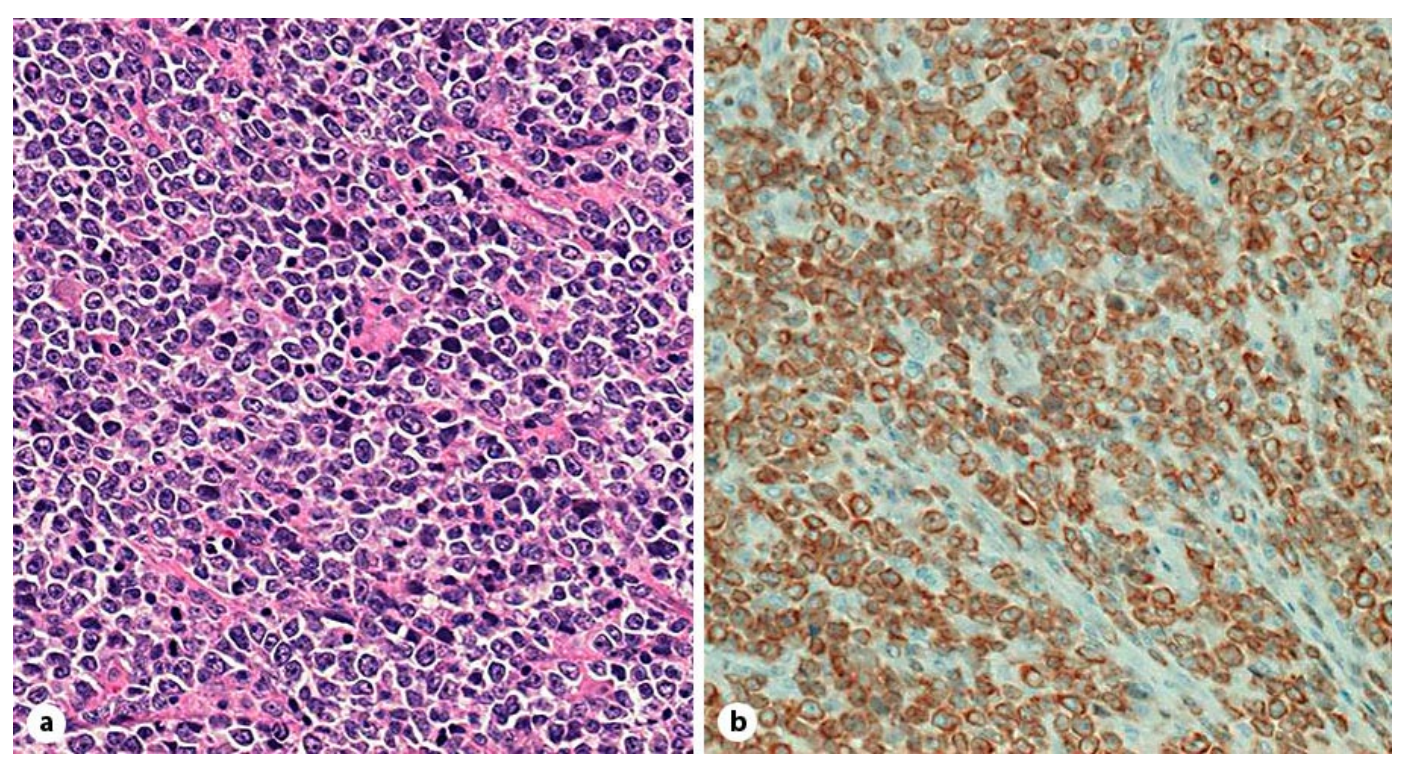




\section{References}

1 Takemoto T, Nezu R, Fujii M, et al: A surgical case of primary malignant T-cell lymphoma of the stomach. J Jpn Surg Assoc 2005;66:1323-1327.

2 Mori S: Pyothorax-associated lymphoma (PAL); in Kikuchi M, Mori S (eds): New Atlas of Malignant Lymphoma. Tokyo, Bunkoudou, 2004, pp 187-189.

3 Aozasa K, Takakuwa T, Nakatsuka S: The growth of malignant lymphoma caused by chronic inflammation. J Jpn Soc Intern Med 2001;90:1019-1023.

4 Mori S, Katano H: Primary effusion lymphoma (PEL); in Kikuchi M, Mori S (eds): New Atlas of Malignant Lymphoma. Tokyo, Bunkoudou, 2004, pp 183-186.

-5 Lister TA, Crowther D, Sutcliffe SB, et al: Report of a committee convened to discuss the evaluation and staging of patients with Hodgkin's disease: Cotswolds meeting. J Clin Oncol 1989;7:1630-1636.

6 Ooshima K: Peripheral T-cell lymphoma, unspecified (PTCL, unspecified); in Kikuchi M, Mori S (eds): New Atlas of Malignant Lymphoma. Tokyo, Bunkoudou, 2004, pp 251-255.

7 Jaffe ES, Harris NL, Stein H, et al: Pathology and Genetics: Tumours of Haematopoietic and Lymphoid Tissues. Lyon, IARC Press, 2001.

8 Shigeoka Y, Itou K, Ootsu T: Treatment strategy of gastric lymphoma. J Jpn Soc Intern Med 2001;90:1003-1009.

-9 Dawson IM, Cornes JS, Morson BC: Primary malignant lymphoid tumours of the intestinal tract. Report of 37 cases with a study of factors influencing prognosis. Br J Surg 1961;49:80-89.

-10 Cesarman E, Nador RG, Aozasa K, et al: Kaposi's sarcoma-associated herpesvirus in non-AIDS related lymphomas occurring in body cavities. Am J Pathol 1996;149:53-57.

11 Matsuba Y, Oka A, Niimi K, et al: A case of primary gastric T-cell malignant lymphoma. J Jpn Surg Assoc 2006;67:59-63. 